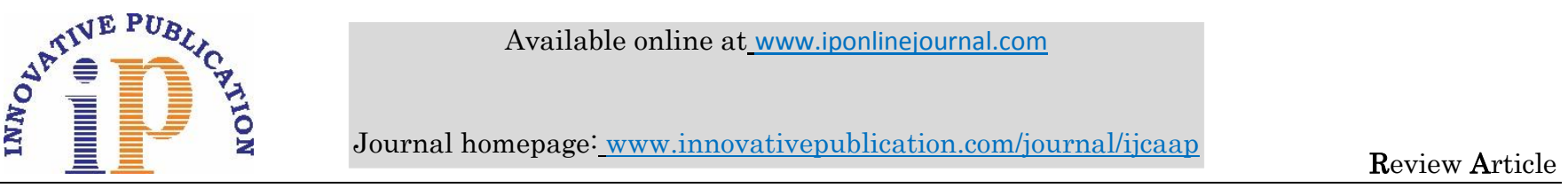

\title{
A concise review on analytical profile of naproxen
}

\section{Pritam's Jain}

Associate Professor, R. C. Patel institute of pharmaceutical education and research, Shirpur, Maharashtra, India

\begin{abstract}
Naproxen (NAP) is a Non-steroidal anti-inflammatory drugs (NSAID) used in the treatment of pain or inflammation caused by situations such as arthritis, ankylosing spondylitis, tendinitis, bursitis, gout, or menstrual cramps. Nap is available in isolated dosage from with various similar anti- inflammatory drugs, esomeprazole, pantoprazole, paracetamol, ranitidine, sumatriptan and ibuprofen. The present exploration evaluates the various method for analysing of NAP in bulk drugs and formulated products. A summarizing review characterizes the gathering and conversation of about more than 62 analytical methods which includes HPLC, HPTLC, UV-Spectrophotometry, capillary electrophoresis, electrochemical methods. HPLC technique are provided in Table03 and Table 04 for NAP alone and combination, including parameters such as matrix, stationary phase, mobile phase, wavelength detection etc. and HPTLC methods are reported in Table 05 with parameters like stationary phase, mobile phase combination, $\mathrm{R}_{\mathrm{F}}$ etc. Method of UV-Spectrophotometry applied for examination of NAP in biological mediums, bulk sample and in various dosage formulation. Spectrometric methods for NAP alone and in mixture are given in Table 08 which includes parameters like $\lambda$ max, solvent, matrix etc.
\end{abstract}

Keywords: Naproxen, HPLC, HPTLC, UV-Spectrophotometric, LC-MS/MS.

\section{Introduction}

Naproxen is a structurally [(S)-6-methoxy-alpha-methyl-2naphthaleneacetic acid] action has non-steroidal antiinflammatory medicine that shows both antipyretic and analgesic behavniour. ${ }^{1}$ Naproxen formulation is Artagen, Arthopan and Napexar formed by Ranbaxy.

The mechanism action of naproxen, similar to that of other NSAIDs, has believed to be related with Cyclooxygenase activity inhibition.COX-1 inhibition should be complementary to gastrointestinal and renal toxicity while COX-2 inhibition is anti-inflammatory. ${ }^{2}$ Similar to added NSAIDS naproxen is capable of creating troubles in the gastro intestinal tract naproxen is practically insoluble in water, soluble in ethanol 96 percent and pka in methanol 4.2. ${ }^{3}$ Naproxen is generally metabolized to 6-0-desmethyl naproxen and mutually parent and metabolized do not produce metabolizing enzymes. The practically observed incurable exclusion half-life is almost 15 hours. Naproxen is normally used for the reduction of fever, pain also inflammation and stiffness caused by in conditions including of osteoarthritis, migraine, rheumatoid arthritis, psoriatic arthritis, kidney stone, gout, kidney stone, menstrual cramps,ankylosing spondylitis, tendinitis and bursitis. $^{4}$

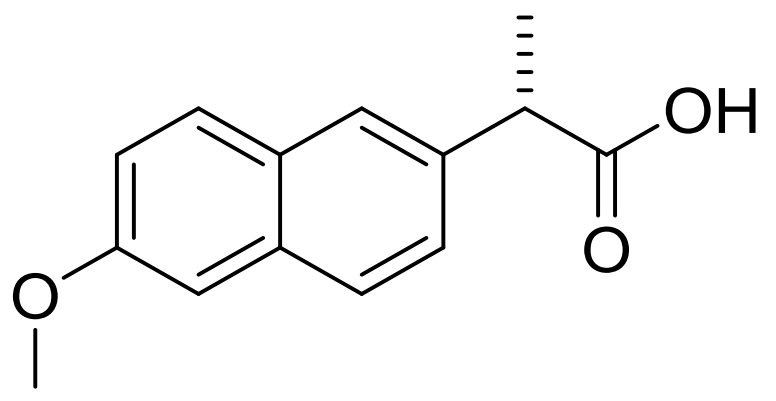

Fig. 1: Chemical structure of Naproxen

\section{Mechanism of action}

The mainly mechanism action of naproxen is its inhibition of production prostaglandin of by binding reversibly to cyclooxygenase. This have first enzyme in the arachidonic acid cascade that results in the synthesis of prostaglandins. By lowering the levels of these abundant substances, naproxen affects pain, inflammation, fever, uterine contractility, platelet aggregation, and vasoactivity, all of which are mediated by prostaglandins and related thromboxanes and prostacyclin. All non-steroidal antiinflammatory preparations appear to act same by blocking the cyclooxygenase stage in the cascade. ${ }^{5}$

\section{Pharmacokinetic data \\ Bioavailability}

Naproxen is one of the fastly and completely produced in the GI tract with an in vivo bioavailability of $95 \%$. Although naproxen itself is good absorbed, the sodium salt form is more speedily absorbed resulting in greater

*Corresponding Author: Pritam's Jain, Associate Professor, R. C. Patel institute of pharmaceutical education and research, Shirpur, Maharashtra, India

Email: pritash79@yahoo.com

http://doi.org/10.18231/j.ijcaap.2019.016 
maximum plasma concentration at specified dose. Food causes a minor decrease inabsorption rate.

\section{Protein binding}

Therapeutic levels of Naproxen $>99 \%$ albumin-bound.

\section{Metabolism}

Naproxen and Parent as well as and metabolites do not couse enzyme metabolizer. Naproxen is widely metabolized to 6-0-desmethyl

\section{Half-life}

The practically observed elimination of half-life is approximately 15 hours.

\section{Excretion}

$0.13 \mathrm{~mL} / \mathrm{kg}$ clearance of naproxen. Almost $95 \%$ of the naproxen from any dose is excreted in the urine, mostly as naproxen (Less than 4\%), 6-0-desmethyl naproxen (less than $1 \%)$ or their conjugates $(66 \%-92 \%)$.

\section{Clinicaluse}

Naproxen if used to relive pain from various circumstances, including headaches, muscle aches, tendonitis, dental suffering, and cramps of menstruation. It also decreases arthritis, bursitis, and gout assaults pain, inflammation, and joint stiffness.

\section{Adverse effects}

Naproxen was correlated with the lowest general cardio vascular risk of all the NSAIDs assessed.

As with other NSAIDs, naproxen may trigger gastrointestin al issues such as heartburn, constipation, diarrhea, ulcers, an $\mathrm{d}$ swelling in the stomach. It may interfere with and decreas e the efficacy of SSRI antidepressants. ${ }^{6}$

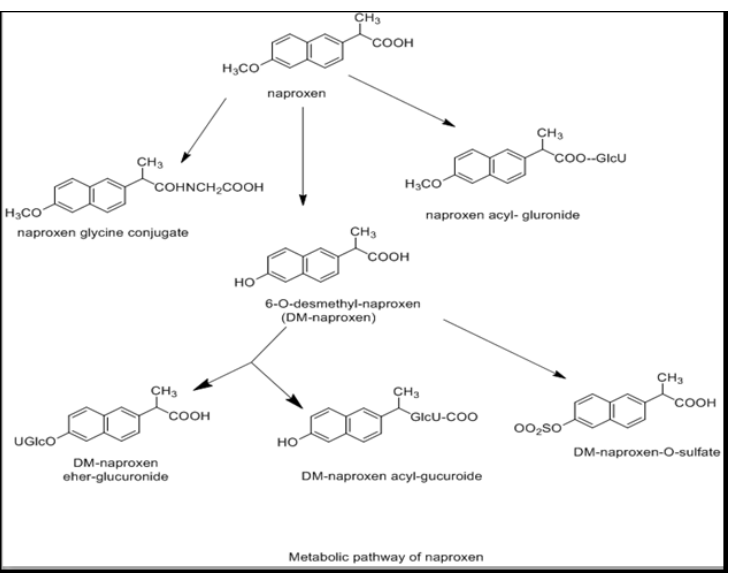

Fig. 2: Metabolite pathway of naproxen

\section{Metabolite}

The 6-O-desmethylated metabolite (DMnaproxen) is unchanged excreted and combined with sulfate and glucuronic acid The 6-O-desmethylated metabolite (DM-naproxen) is excreted unaffected as well as combination with glucuronic acid and sulphate. ${ }^{7}$

\section{Analytical accounts on naproxen}

The general literature survey discovered, several analytical method viz UV/Visible- Spectrophotometry, Spectrofluorimetry, HPLC, HPTLC and LC-MS for the resolve of NAP in bulk and pharmaceutical product. The recorded methods describe the determination of naproxen in different dosage forms as single component and in mixture with esomeprazole, domperidone, sumatriptan succinate, pantoprazole, rabeprazole, pseudoephedrine, paracetamol, ranitidine hydrochloride, diphenhydramine hydrochloride. Fig. 4 shows different analytical methods implemented for assessment of naproxen. ${ }^{8}$

\section{Analytical method for Naproxen}

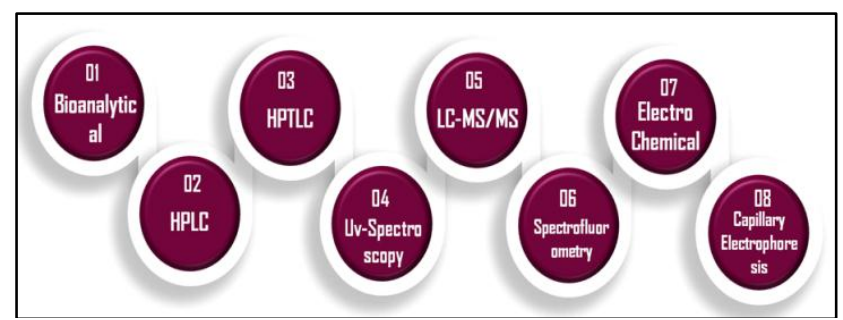

Fig. 4: Analytical accounts on Naproxen

Table 1: Dosage forms, route of administration and recommended dose of NAP

\begin{tabular}{|c|l|l|}
\hline Dosage forms & \multicolumn{1}{|c|}{$\begin{array}{c}\text { Route of } \\
\text { administration }\end{array}$} & \multicolumn{1}{|c|}{ Indication/dose } \\
\hline Tablet and suspension & & $\begin{array}{l}\text { Usual Adult Dose of Ankylosing Spondylitis- 250 mg to 500 mg } \\
\text { (naproxen) or 275 mg to 550 mg (naproxen sodium)twice daily orally }\end{array}$ \\
& & $\begin{array}{l}\text { Usual Adul Dose of Rheumatoid Arthritis-250 mg to 500 mg } \\
\text { (naproxen) or 275 mg to 550 mg (naproxen sodium) twice daily orally }\end{array}$ \\
Tablet and suspension & & Usual Adult Dose for Acute Gout-750 mg \\
\hline Tablet & &
\end{tabular}




\begin{tabular}{|c|l|l|}
\hline Tablet & \multirow{2}{*}{$\begin{array}{l}\text { Usual youth dose of paediatric Rheumatoid Arthritis-older than 2 years: } \\
5 \mathrm{mg} / \mathrm{kg} \text { orally twice a day }\end{array}$} \\
& $\begin{array}{l}\text { Usual Adult Dose for Osteoarthritis-250 mg to } 500 \mathrm{mg} \text { (naproxen) or } \\
275 \mathrm{mg} \text { to } 550 \mathrm{mg} \text { (naproxen sodium) twice daily orally }\end{array}$ \\
Tablet and suspension & Usual Pediatric Dose for Childish Rheumatoid Arthritis- \\
\hline Tablet and suspension & Oral &
\end{tabular}

\section{Pharmacopoeial status}

IP portrayed HPLC assay technique consuming a stainless steel $25 \mathrm{~cm}$ x $4.6 \mathrm{~mm}$, packed with silica gel $\pi$-acceptor $/ \pi$ donor for chiral separations $(5 \mu \mathrm{m})$, as a static phase and mobile phase comprised of 5 volumes of a glacial acetic acid, 50 volume of acetonitrile, 100 volume of 2-propanol and 845 volume of hexane, keeping the flow rate of 2 $\mathrm{mL} / \mathrm{min}$. Column effluent was scrutinized on $263 \mathrm{~nm}$, and injection volume set at $20 \mu 1 .{ }^{9}$

\section{Accounts on bio-analytical method for estimation of naproxen}

Bio-analysis is a sub-discipline of analytical chemistry casing the quantitative dimension of xenobiotics and biotic (proteins, macromolecules, DNA, metabolites, molecule of drugs,) in biological systems. ${ }^{10}$

\section{Literature survey exposed that HPLC is predominantly} used for the bio-analysis of Naproxen

S. Ashutosh Kumar et al (2014) was studied the bioanalytical RP-HPLC technique for simultaneous purpose of ESOM and NAP in human plasma was established and validated as per US-FDA guidelines, by consuming symmetry C18 $(250 \mathrm{~mm} \times 4.6 \mathrm{~mm}, 5250 \mathrm{~mm}, 5 \mu \mathrm{m})$ XTerra column and potassium dihydrogen phosphate and acetonitrile with mobile phase portion of $60: 40 \mathrm{v} / \mathrm{v}$ at a pour rate of $1.0 \mathrm{ml} / \mathrm{min}$. $1.0-6.0 \mu \mathrm{g} / \mathrm{ml}$ concentration range was selected for ESOM and NAP 25.0-150.0 $\mu \mathrm{g} / \mathrm{ml}$, and 0.999 correlation coefficient of both drugs respectively ESOM and NAP. The assay of allowable measurement of ESOM and NAP was found to be $0.04 \mu \mathrm{g} / \mathrm{ml}$ both drugs. The average recovery for the drug ESOM and NAP was found to be 98.97-99-84 and 99.80-100.95. ${ }^{11}$

Bilal Yilmaz et al. (2013) recognized a validated simple HPLC tecnique has been recognized for the resolution of NAP in human plasma. The detection was accomplished on an Ace $\mathrm{C} 18$ column using UV-Detection. The mobile phase having of $20 \mathrm{~mm}$ phosphate buffer $(\mathrm{pH} 7)$ containing $0.1 \%$ trifluroacetic acid: acetonitrile (65:35) v/v and The linearity was reliable in series of 0.10 and $5.0 \mathrm{mg} / \mathrm{ml}$. precision (intra-day, inter-day)correctness morals for NAP in plasma were less than 4.84, and accuracy (reasonable error) was better than $3.67 \%$.

Nap's extraction percent retrieval trials since human plasma were discovered to be 91.0 and $98.9 \%$. The LOD and LOQ weredicoverd to be 0.03 and $0.10 \mathrm{mg} / \mathrm{ml}$, respectively. This assaywas also helpful in regulating NAP pharmacokinetic variables in six energetic Turkish volunteers who needed to remain given $220 \mathrm{mg}$ of NAP. ${ }^{12}$

Table 2: Bio-Analytical NAP technique

\begin{tabular}{|c|c|c|c|c|c|c|c|}
\hline S. No. & Drug & $\begin{array}{l}\text { Sample } \\
\text { Matrix }\end{array}$ & Method & Column & Detection & $\begin{array}{c}\text { Internal } \\
\text { Standard }\end{array}$ & Ref \\
\hline 1. & NAP & $\begin{array}{l}\text { Human } \\
\text { plasma }\end{array}$ & HPLC & $\mathrm{C} 18$ & - & Ibuprofen & 12 \\
\hline 2. & NAP & $\begin{array}{l}\text { Human } \\
\text { plasma }\end{array}$ & HPLC & C18 & $254 \mathrm{~nm}$ & $\begin{array}{l}\text { ACN (Human } \\
\text { Plasma) }\end{array}$ & 13 \\
\hline 3. & $\begin{array}{l}\text { NAP, } \\
\text { PARA }\end{array} \quad$ IBFN and & $\begin{array}{l}\text { Human } \\
\text { plasma }\end{array}$ & HPLC-UV & Zorbax SB-C18 & $232 \mathrm{~nm}$ & Fenoprofen & 14 \\
\hline 4. & NAP and ESOM & $\begin{array}{l}\text { Human } \\
\text { plasma }\end{array}$ & LC-MS/MS & XBridge C18 & - & Ibuprofen & 15 \\
\hline 5. & $\begin{array}{l}\text { Atenolol, } \\
\text { Rosuvastatin, } \\
\text { Spironolactone } \\
\text { Glibenclamide and } \\
\text { NAP Sodium }\end{array}$ & $\begin{array}{l}\text { Human } \\
\text { plasma }\end{array}$ & RP-HPLC & $\mathrm{C} 18$ & $235 \mathrm{~nm}$ & Flurbiprofen & 16 \\
\hline 6. & NAP & $\begin{array}{c}\text { Human } \\
\text { Urine }\end{array}$ & HPLC & C18 & - & - & 17 \\
\hline 7. & ESOM and NAP & $\begin{array}{l}\text { Human } \\
\text { plasma }\end{array}$ & RP-HPLC & $\mathrm{C} 18$ & $285 \mathrm{~nm}$ & - & 18 \\
\hline 8. & NAP & $\begin{array}{l}\text { Human } \\
\text { plasma }\end{array}$ & LC-MS/MS & - & - & Ketoprofen & 19 \\
\hline 9. & NAP & $\begin{array}{l}\text { Human } \\
\text { plasma }\end{array}$ & LC-MS/MS & $\mathrm{C} 18$ & - & Zidovudine & 20 \\
\hline 10. & NAP and BPB & $\begin{array}{c}\text { Human } \\
\text { Serum }\end{array}$ & Spectrophotometry & - & $432 \mathrm{~nm}$ & - & 21 \\
\hline
\end{tabular}




\section{Chromatography overview}

\section{HPLC [High Performance Liquid Chromatography]}

In pharmaceutical formulations, apart from pharmacopeial $\mathrm{t}$ echniques, many HPLC techniques have been recorded for NAP determination.Table 3 shows the summary of the repor ted HPLC technique specifying the mobile phase used for determination, sample matrix, $\pi \max$ and linearity.

The instrumentation of HPLC techniques for NAP deter mination is summarized in Table 4. Sagar D. Solanki et al. (2011). Reported the simple RP-HPLC tenique were set up and validated for purpose of NAP sodium and SUM succinate in dosage form tablet. The mobile phase system is a blend of $\mathrm{H}_{2} \mathrm{O}$ : ACN $(60: 40 \mathrm{v} / \mathrm{v})$ and $0.5 \%$ trifluro acetic acid was added in water, and flow rate of $1.0 \mathrm{ml} / \mathrm{min}$. The keeping wavelength of PDA detector at $277 \mathrm{~nm}$. For both drug, a linear calibration curve is began in the $5-80 \mu \mathrm{g} / \mathrm{ml}$ concentration sequence.

The technique has been validated for parameters such a s specificity, accuracy, precision and linarity. The percent recovery was discovered to range from $98.0 \%$ to $102.0 \%$ to the marked value. The presented method was used efficiently for repeated quantitative analysis of tablets contai ning naproxen and sumatriptan. ${ }^{22}$

Md. Shozan Mondal

et al.

(2011)

Reported the easy, sensitive and specific RP-PLC technique for assessing NAP and DOM in tablet dosage form, accomplished with a shim-pack C18 column $(250 \mathrm{~mm} \times 4.6$ $\mathrm{mm} 5 \mu \mathrm{m}$ ), with a movable phase system is a blend of phosphate buffer: methanol $(30: 70 \mathrm{v} / \mathrm{v}),(\mathrm{pH}$ attuned to 3.00 with sodium hydroxide), at a flow rate of $1.0 \mathrm{ml} / \mathrm{min}$ using UV finding at $280 \mathrm{~nm}$. The proposed technique is found to be having linear correlation coefficient of $r^{2}=0.999$ for NAP and DOM), exact with $99.5 \%$ recovering for DOM and $99.39 \%$ recovery for NAP and precise $(\% \mathrm{RSD} \leq 1 \%)$. This method used for the identify potency of profitable product and potency was found within limit. The technique can be used in tablet dosage for NAP and DOM assessment. $^{23}$

Table 3: HPLC Method for Naproxen (NAP)

\begin{tabular}{|c|c|c|c|c|c|c|c|c|c|}
\hline S. No & Drug & Method & Matrix & Column & Mobile Phase & $\begin{array}{l}\text { Flow } \\
\text { rate }\end{array}$ & Detector & $\mathbf{R t}$ & Ref \\
\hline 1 & NAP & RP-HPLC & Bulk & C18 & $\begin{array}{l}\text { Phosphate Buffer } \\
\text { Methanol 40:60 (v/v). }\end{array}$ & $\begin{array}{c}1.3 \\
\mathrm{ml} / \mathrm{min}\end{array}$ & $\begin{array}{c}\text { UV- } \\
\text { Detector }\end{array}$ & $\begin{array}{c}\text { NAP- } \\
5.82\end{array}$ & 24 \\
\hline 2 & NAP & HPLC & Tablet & - & $\begin{array}{l}\text { Acetonitrile and } 10 \\
\text { mm Ammonium acetate } \\
\text { buffer } \mathrm{pH} 3.8 \text { in ratio 550:450 } \\
\text { v/v (pH } 3.8 \text { adjusted with } \\
\text { acetic acid) }\end{array}$ & $\begin{array}{c}1.0 \\
\mathrm{ml} / \mathrm{min}\end{array}$ & - & $\begin{array}{l}5.9 \pm 0.01 \\
\text { min. }\end{array}$ & 25 \\
\hline 3 & NAP & RP-HPLC & $\begin{array}{l}\text { Dosage } \\
\text { form }\end{array}$ & $\mathrm{C} 18$ & $\begin{array}{l}\text { Acetonitrile: } 0.5 \text { M potassium } \\
\text { dihydrogen phosphate buffer } \\
\text { pH } 2.5 \text { adjusted with ortho- } \\
\text { phosphoric acid: } \\
\text { tetrahydrofuran ( } 45: 53: 2 \\
\text { v/v/v). }\end{array}$ & $\begin{array}{c}1.0 \\
\mathrm{ml} / \mathrm{min}\end{array}$ & $\begin{array}{c}\text { UV- } \\
\text { Detector }\end{array}$ & $3.25 \mathrm{~min}$. & 26 \\
\hline 4 & NAP & RP-HPLC & $\begin{array}{c}\text { Bulk } \\
\text { and } \\
\text { Tablet }\end{array}$ & C18 & $\begin{array}{l}\text { Ammonium acetate } \\
\text { Buffer: Methanol } \\
\text { 40:60 (v/v) }\end{array}$ & $\begin{array}{c}1.0 \\
\mathrm{ml} / \mathrm{min}\end{array}$ & $\begin{array}{c}\text { UV- } \\
\text { Detector }\end{array}$ & 3.063 & 27 \\
\hline 5 & NAP & UHPLC & Bulk & $\mathrm{C} 18$ & - & $\begin{array}{c}1.0 \\
\mathrm{ml} / \mathrm{min}\end{array}$ & $\begin{array}{c}\text { UV- } \\
\text { Detector }\end{array}$ & - & 28 \\
\hline
\end{tabular}

Table 4: HPLC methods for analysis of Naproxen in combination

\begin{tabular}{|c|c|c|c|c|c|c|c|c|c|}
\hline S. No & Drug & Method & Matrix & $\begin{array}{c}\text { Colum } \\
n\end{array}$ & Mobile Phase & $\begin{array}{l}\text { Flow } \\
\text { rate }\end{array}$ & Detector & $\mathbf{R t}$ & Ref \\
\hline 1 & $\begin{array}{l}\text { SUMA and } \\
\text { NAP }\end{array}$ & $\begin{array}{c}\text { RP- } \\
\text { HPLC }\end{array}$ & Tablet & C18 & $\begin{array}{l}\text { ACN: Water }(60: 40) \text { and } \\
0.05 \% \mathrm{v} / \mathrm{v} .\end{array}$ & $\begin{array}{c}1 \\
\mathrm{ml} / \mathrm{min}\end{array}$ & PDA Detector & $\begin{array}{l}\text { SUMA } \\
2.26 \\
\text { NAP } \\
5.79\end{array}$ & 29 \\
\hline 2 & $\begin{array}{l}\text { NAP and } \\
\text { ESOM }\end{array}$ & HPLC & & $\mathrm{C} 18$ & $\begin{array}{l}\text { Phosphate buffer (pH } 6.1) \\
\text { and acetonitrile in ratio of } \\
(40: 60, \mathrm{v} / \mathrm{v} \text {. }\end{array}$ & $\begin{array}{c}1.5 \\
\mathrm{ml} / \mathrm{min}\end{array}$ & UV Detector & $\begin{array}{l}\text { NAP } \\
1.72 \\
\text { ESOM } \\
2.29\end{array}$ & 30 \\
\hline 3 & $\begin{array}{l}\text { DOM and } \\
\text { NAP }\end{array}$ & $\begin{array}{c}\text { RP- } \\
\text { HPLC }\end{array}$ & & $\mathrm{C} 18$ & $\begin{array}{l}\text { Phosphate buffer }(\mathrm{pH} \\
\text { adjusted to } 3.00 \text { with } \\
\text { sodium hydroxide): } \\
\text { methanol in the ratio } \\
30: 70(\mathrm{v} / \mathrm{v})\end{array}$ & $\begin{array}{c}1.0 \\
\mathrm{ml} / \mathrm{min}\end{array}$ & UV Detector & $\begin{array}{l}\text { DOM- } \\
3.17 \\
\text { NAP- } \\
5.42\end{array}$ & 31 \\
\hline 4 & NAP and & RP- & - & $\mathrm{C} 18$ & Phosphate buffer $(\mathrm{pH} 6.5$ & 1.0 & UV Detector & DOM- & 32 \\
\hline
\end{tabular}




\begin{tabular}{|c|c|c|c|c|c|c|c|c|c|}
\hline & DOM & HPLC & & & $\begin{array}{l}\text { adjusted with } \\
\text { orthophosphoric acid) } \\
\text { and acetonitrile in the } \\
\text { ratio of } 50: 50(\mathrm{v} / \mathrm{v})\end{array}$ & $\mathrm{ml} / \mathrm{min}$ & & $\begin{array}{l}2.63 \\
\text { NAP- } \\
4.27\end{array}$ & \\
\hline 5 & $\begin{array}{l}\text { NAP and } \\
\text { ESOM }\end{array}$ & $\begin{array}{l}\text { RP- } \\
\text { HPLC }\end{array}$ & - & - & $\begin{array}{l}\text { Acetonitrile: } \\
\text { Methanol in the } \\
\text { Ratio of } 60: 40 \\
(\mathrm{v} / \mathrm{v}) \text {. }\end{array}$ & $\begin{array}{c}1.0 \\
\mathrm{ml} / \mathrm{min}\end{array}$ & UV-Detector & $\begin{array}{l}\text { ESOM- } \\
3.425 \\
\text { NAP- } \\
4.352\end{array}$ & 33 \\
\hline 6 & $\begin{array}{c}\text { SUMA and } \\
\text { NAP }\end{array}$ & $\begin{array}{c}\text { RP- } \\
\text { HPLC }\end{array}$ & $\begin{array}{c}\text { Bulk and } \\
\text { Tablet }\end{array}$ & $\mathrm{C} 18$ & $\begin{array}{l}\text { Water: } \\
\text { Methanol in } \\
\text { The ratio of } \\
55: 45(\mathrm{v} / \mathrm{v})\end{array}$ & $\begin{array}{c}1.0 \\
\mathrm{ml} / \mathrm{min}\end{array}$ & $\begin{array}{c}\text { UV- } \\
\text { Detector }\end{array}$ & $\begin{array}{l}\text { SUM- } \\
2.90 \\
\text { NAP- } \\
3.480 \\
\end{array}$ & 34 \\
\hline 7 & $\begin{array}{l}\text { NAP and } \\
\text { PAN }\end{array}$ & $\begin{array}{c}\text { RP- } \\
\text { HPLC }\end{array}$ & Capsule & $\mathrm{C} 18$ & $\begin{array}{l}\text { Phosphate } \\
\text { buffers } \\
\text { (K2HPO4,KH2PO4) } \\
\text { (PH:6.5) Acetonitrile } \\
(55: 45 \mathrm{v} / \mathrm{v})\end{array}$ & $\begin{array}{c}1.0 \\
\mathrm{ml} / \mathrm{min}\end{array}$ & - & $\begin{array}{l}\text { NAP- } \\
3.357 \\
\text { PAN- } \\
4.907 \\
\end{array}$ & 35 \\
\hline 8 & $\begin{array}{l}\text { NAP and } \\
\text { PAN }\end{array}$ & $\begin{array}{l}\text { RP- } \\
\text { HPLC }\end{array}$ & Capsule & $\mathrm{C} 18$ & $\begin{array}{l}\text { Methanol: phosphate } \\
\text { buffer }(5.4) \text { in the ratio of } \\
70: 30(\mathrm{v} / \mathrm{v}) \text {. }\end{array}$ & $\begin{array}{c}1.0 \\
\mathrm{ml} / \mathrm{min}\end{array}$ & $\begin{array}{l}\text { PDF- } \\
\text { Detector }\end{array}$ & $\begin{array}{c}\text { NAP- } \\
3.33 \\
\text { PENTO- } \\
1.90\end{array}$ & 36 \\
\hline 9 & $\begin{array}{c}\text { ESOM and } \\
\text { NAP }\end{array}$ & $\begin{array}{c}\text { RP- } \\
\text { HPLC }\end{array}$ & & C18 & $\begin{array}{l}\text { Acetonitrile: } \\
\text { Phosphate buffer } \\
(\mathrm{pH} 7.0) \text { in the ratio } \\
\text { Of 50:50 (v/v) }\end{array}$ & $\begin{array}{c}0.5 \\
\mathrm{ml} / \mathrm{min}\end{array}$ & $\begin{array}{c}\text { PDF- } \\
\text { Detector }\end{array}$ & ESO- & 37 \\
\hline 10 & $\begin{array}{l}\text { NAP and } \\
\text { ESOM }\end{array}$ & HPLC & & $\mathrm{C} 18$ & $\begin{array}{l}\text { Buffer: } \\
\text { Methanol = 50:40:10 add } \\
0.1 \% \text { v/v Triethylamine } \\
\text { in above mixture and } \\
\text { finally adjust with glacial } \\
\text { acetic acid to a pH 7.0. }\end{array}$ & $\begin{array}{c}1.0 \\
\mathrm{ml} / \mathrm{min}\end{array}$ & $\begin{array}{c}\text { UV- } \\
\text { Detector }\end{array}$ & - & 38 \\
\hline 11 & $\begin{array}{l}\text { NAP and } \\
\text { ESOM }\end{array}$ & $\begin{array}{c}\text { RP- } \\
\text { HPLC }\end{array}$ & Tablet & $\mathrm{C} 18$ & $\begin{array}{l}\text { Buffer, Acetonitrile and } \\
\text { Methanol in } \\
\text { the ratio of }(70: 20: 10) \\
\text { v/v/v. }\end{array}$ & $\begin{array}{c}1.5 \\
\mathrm{ml} / \mathrm{min}\end{array}$ & $\begin{array}{c}\text { UV- } \\
\text { Detector }\end{array}$ & $\begin{array}{l}\text { NAP- } \\
3.352 \\
\text { ESO- } \\
6.112\end{array}$ & 39 \\
\hline 12 & $\begin{array}{l}\text { NAP and } \\
\text { RAB }\end{array}$ & $\begin{array}{c}\text { RP- } \\
\text { HPLC }\end{array}$ & Bulk & C18 & $\begin{array}{l}\text { Sodium dihydrogen } \\
\text { Buffer: Acetonitrile in the } \\
\text { ratio of } 70: 30 \\
(\mathrm{v} / \mathrm{v})\end{array}$ & $\begin{array}{c}1.0 \\
\mathrm{ml} / \mathrm{min}\end{array}$ & $\begin{array}{c}\text { UV- } \\
\text { Detector }\end{array}$ & $\begin{array}{c}\text { NAP- } \\
3.33 \pm 0.0 \\
27 \\
\text { RAB- } \\
7.61 \pm 0.0 \\
43 \\
\end{array}$ & 40 \\
\hline 13 & $\begin{array}{l}\text { NAP and } \\
\text { SUMA }\end{array}$ & $\begin{array}{c}\text { RP- } \\
\text { HPLC }\end{array}$ & $\begin{array}{l}\text { Bulk and } \\
\text { Dosage } \\
\text { form }\end{array}$ & $\mathrm{C} 8$ & $\begin{array}{l}\text { Buffer: Acetonitrile } \\
\text { In the ratio of } 50: 50 \\
(\mathrm{v} / \mathrm{v})\end{array}$ & $\begin{array}{c}0.7 \\
\mathrm{ml} / \mathrm{min}\end{array}$ & $\begin{array}{c}\text { UV- } \\
\text { Detector }\end{array}$ & $\begin{array}{l}\text { NAP- } \\
2.249 \\
\text { SUM- } \\
5.875\end{array}$ & 41 \\
\hline 14 & $\begin{array}{l}\text { NAP and } \\
\text { PEPH }\end{array}$ & HPLC & - & $\begin{array}{l}\text { Spheris } \\
\text { o-rb } \\
\text { Cyano }\end{array}$ & $\begin{array}{l}\text { Water: acetonitrile- } \\
\text { Methanol: triethylamine } \\
\text { mixture in the ratio of } \\
850: 75: 75: 5(\mathrm{v} / \mathrm{v}) \text {. }\end{array}$ & $\begin{array}{c}0.5 \\
\mathrm{ml} / \mathrm{min}\end{array}$ & UV- Detector & $\begin{array}{l}\text { NAP-Na } \\
1.11 \\
\text { PSEH- } \\
0.39 \\
\end{array}$ & 42 \\
\hline 15 & $\begin{array}{c}\text { SUMA and } \\
\text { NAP }\end{array}$ & $\begin{array}{c}\text { RP- } \\
\text { HPLC }\end{array}$ & $\begin{array}{l}\text { Bulk and } \\
\text { Dosage } \\
\text { form }\end{array}$ & C18 & $\begin{array}{l}\text { Acetonitrile: Methanol: } \\
\text { phosphate buffer in the } \\
\text { ratio of 50:10:40 } \\
(\mathrm{v} / \mathrm{v}) \text {. }\end{array}$ & $\begin{array}{c}1.0 \\
\mathrm{ml} / \mathrm{min}\end{array}$ & - & $\begin{array}{l}\text { NAP- } \\
4.037 \\
\text { SUM- } \\
2.813\end{array}$ & 43 \\
\hline 16 & $\begin{array}{l}\text { SUMA and } \\
\text { NAP }\end{array}$ & UPLC & - & $\mathrm{C} 18$ & $\begin{array}{l}\text { Acetonitrile: Water } \\
\text { In the ratio of } 90: 10 \\
(\mathrm{v} / \mathrm{v})\end{array}$ & $\begin{array}{c}1.0 \\
\mathrm{ml} / \mathrm{min}\end{array}$ & $\begin{array}{c}\text { UV- } \\
\text { Detector }\end{array}$ & $\begin{array}{l}\text { SUM- } \\
1.7 \\
\text { NAP- } \\
2.7 \\
\end{array}$ & 44 \\
\hline 17 & $\begin{array}{c}\text { PARA and } \\
\text { NAP }\end{array}$ & $\begin{array}{c}\text { RP- } \\
\text { HPLC }\end{array}$ & Tablet & C18 & $\begin{array}{l}\text { Water: Acetonitrile in the } \\
\text { ratio of } 87: 13 \\
(\mathrm{v} / \mathrm{v})\end{array}$ & $\begin{array}{c}1.0 \\
\mathrm{ml} / \mathrm{min}\end{array}$ & $\begin{array}{c}\text { UV- } \\
\text { Detector }\end{array}$ & $\begin{array}{l}\text { PARA- } \\
3.005 \\
\text { NAP- } \\
7.402\end{array}$ & 45 \\
\hline 18 & $\begin{array}{l}\text { ESOM and } \\
\text { NAP }\end{array}$ & $\begin{array}{c}\text { RP- } \\
\text { HPLC }\end{array}$ & $\begin{array}{c}\text { Bulk and } \\
\text { Tablet }\end{array}$ & C18 & $\begin{array}{l}\text { Phosphate buffer ( } \mathrm{pH} 3) \\
\text { and Acetonitrile }\end{array}$ & $\begin{array}{c}1.0 \\
\mathrm{ml} / \mathrm{min}\end{array}$ & $\begin{array}{l}\text { DAD and UV } \\
\text { Detector }\end{array}$ & $\begin{array}{l}\text { ESO- } \\
2.105\end{array}$ & 46 \\
\hline
\end{tabular}




\begin{tabular}{|c|c|c|c|c|c|c|c|c|c|}
\hline & & & & & 60: $40(\mathrm{v} / \mathrm{v})$ & & & $\begin{array}{l}\text { PAN- } \\
3.555\end{array}$ & \\
\hline 19 & $\begin{array}{l}\text { DIFL and } \\
\text { NAP }\end{array}$ & HPLC & Tablet & C18 & $\begin{array}{l}\text { Acetonitrile: } \\
\text { buffer }(\mathrm{pH} 4.2 ; 50 \mathrm{~mm}) \\
(60: 40, \mathrm{v} / \mathrm{v}) .\end{array}$ & $\begin{array}{c}0.7 \\
\mathrm{ml} / \mathrm{min}\end{array}$ & $\begin{array}{l}\text { UV-VIS } \\
\text { Detector }\end{array}$ & - & 47 \\
\hline 20 & $\begin{array}{l}\text { RAN, } \\
\text { DOM and } \\
\text { NAP }\end{array}$ & $\begin{array}{c}\text { RP- } \\
\text { HPLC }\end{array}$ & - & - & $\begin{array}{l}0.1 \text { M Orthophosphoric } \\
\text { acid } \\
\text { solution }(\mathrm{pH} 3.0) \text { : } \\
\text { methanol }(35: 65 \mathrm{v} / \mathrm{v})\end{array}$ & $\begin{array}{c}1.0 \\
\mathrm{ml} / \mathrm{min}\end{array}$ & $\begin{array}{c}\text { UV- } \\
\text { Detector }\end{array}$ & $\begin{array}{l}\text { RAN- } \\
2.702 \\
\text { DON- } \\
3.666 \\
\text { NAP- } \\
9.842\end{array}$ & 48 \\
\hline 21 & $\begin{array}{l}\text { NAP and } \\
\text { PEPH }\end{array}$ & HCL & Tablet & $\mathrm{C} 18$ & $\begin{array}{l}0.2 \mathrm{M} \text { acetate } \\
\text { buffer and Acetonitrile } \\
(40: 60)(\mathrm{v} / \mathrm{v}) .\end{array}$ & $\begin{array}{c}1.7 \\
\mathrm{ml} / \mathrm{min}\end{array}$ & PDA Detector & $\begin{array}{c}\text { NAP- } \\
5.87 \\
\text { PSE- } \\
1.345 \\
\text { IS- } \\
2.91\end{array}$ & 49 \\
\hline 22 & $\begin{array}{l}\text { NAP and } \\
\text { ESOM }\end{array}$ & $\begin{array}{c}\text { RP- } \\
\text { HPLC }\end{array}$ & $\begin{array}{l}\text { Tablet } \\
\text { and } \\
\text { Dosage } \\
\text { form }\end{array}$ & $\mathrm{C} 18$ & $\begin{array}{l}\text { Buffer } \\
\text { [tetrabutylammonium } \\
\text { hydroxide and n-heptane } \\
\text { sulfonic acid-Na salt } \\
\text { acetonitrile and methanol } \\
\text { in a } 60: 20: 20 \mathrm{v} / \mathrm{v} / \mathrm{v} \text { ratio }\end{array}$ & $\begin{array}{c}1.0 \\
\mathrm{ml} / \mathrm{min}\end{array}$ & $\begin{array}{c}\text { UV- } \\
\text { Detection }\end{array}$ & $\begin{array}{l}\text { NAP - } \\
4.9 \pm 0.1 \\
\text { min, } \\
\text { ESP } \\
6.8 \pm 0.1 \\
\text { min. }\end{array}$ & 50 \\
\hline 23 & $\begin{array}{l}\text { EOME and } \\
\text { NAP }\end{array}$ & $\begin{array}{c}\text { RP- } \\
\text { HPLC }\end{array}$ & $\begin{array}{c}\text { Bulk and } \\
\text { Tablet }\end{array}$ & C18 & $\begin{array}{l}\text { Acetonitrile: } \\
\text { potassium dihydrogen } \\
\text { phosphate buffer } \\
(60: 40 \mathrm{v} / \mathrm{v}) \text {. }\end{array}$ & $\begin{array}{c}1.0 \\
\mathrm{Ml} / \mathrm{min}\end{array}$ & $\begin{array}{c}\text { UV- } \\
\text { Detector }\end{array}$ & $\begin{array}{l}\text { ESO- } \\
3.052 \\
\text { NAP- } \\
6.140\end{array}$ & 51 \\
\hline 24 & $\begin{array}{c}\text { NAP and } \\
\text { DIPH HCL }\end{array}$ & $\begin{array}{c}\text { RP- } \\
\text { HPLC }\end{array}$ & $\begin{array}{c}\text { Bulk and } \\
\text { Tablet }\end{array}$ & $\mathrm{C} 18$ & $\begin{array}{l}15 \mathrm{mM} \text { ammonium acetate } \\
\text { buffer: Acetonitrile } \\
(60: 40 \mathrm{~V} / \mathrm{V}) .\end{array}$ & $\begin{array}{c}1.0 \\
\mathrm{ml} / \mathrm{min}\end{array}$ & $\begin{array}{c}\text { PDA- } \\
\text { Detector }\end{array}$ & $\begin{array}{l}\text { NAP } \\
4.49 \\
\text { DPH } \\
10.80\end{array}$ & 52 \\
\hline
\end{tabular}

\section{High performance thine layer chromatography (HPTLC)}

Six easy HPTLC techniques were studied for simultaneous NAP estimation in mixed dosage from with SUMA, PAN, DOM and DIPHY. Table 5 shows the overview of the reported HPTLC techniques.

Riddhi Gondalia et al. (2011) created and validated a straightforward mixed dosage technique for NAP and SUMA, a co nventional NAP and SUMA solution for percolated silica gel 60F 254, and a mobile phase for methanol growth: distilled wat er: formic acid ratio of 0.5:7.5:0.1 (v/v/v), The accuracy and precision of the suggested technique were analysed by the recovery study and the\% recovery for SUMA was 99.255 and $99.0 .3 \%$ respectively, and behind development, plates were observed under UV light. The detector response for NAP sodium and SUMA succinate was linearity in the range of 200-1200 ng / spot and 100-1000 ng / spot.

Shubhangi M. Pawar (2010), Investigation of a easy, accurate and precise high-performance thin-layer chromatography technique for simultaneously quantify action of DOM-S and NAP-S as bulk drug and in tablet dosage form. The stationary phase was carried out on aluminum plates pre-coated with silica gel $60 \mathrm{~F} 254$, and mobile phase was toluene: methanol: acetone (8: $2: 2, \mathrm{v} / \mathrm{v} / \mathrm{v})$, and $\mathrm{Rf}$ value was found to be $0.44 \pm 0.02$ and $0.5 \pm 0.02$ for DOM-S and NAP-S, respectively. The densitometric scanning was done at $266 \mathrm{~nm}$. The linearity range was chosen by $20-140 \mathrm{ng}$. spot-1 for DOM and 500-3500 ng. spot-1 for NAP,), precision (intra-day RSD0.4-1.01\% and inter-day RSD $0.316-0.876 \%$ for DOM, and intra-day RSD $0.488-1.329 \%$ and inter-day RSD $0.450-1.026 \%$ for NAP), and accuracy $(98.38 \pm 0.55 \%$ for DOM and $98.64 \pm 0.49 \%$ for NAP), specificity, in accordance with ICH guidelines. ${ }^{54}$

Table 5: HPTLC Method for determination of Naproxen

\begin{tabular}{|c|c|c|c|c|c|c|c|c|}
\hline S. No & Drugs & Matrix & $\begin{array}{c}\text { Stationary } \\
\text { phase Plates }\end{array}$ & $\begin{array}{l}\text { Mobile phase } \\
\text { composition }\end{array}$ & $\begin{array}{l}\text { Detection } \\
\text { (nm) }\end{array}$ & Linearity & Rf & Ref \\
\hline 1 & $\begin{array}{c}\text { NAP } \\
\text { and } \\
\text { SUMA }\end{array}$ & $\begin{array}{c}\text { Dosage } \\
\text { form }\end{array}$ & $\begin{array}{c}\text { Silica gel } \\
60 \mathrm{~F} 254\end{array}$ & $\begin{array}{l}\text { Methanol: } \\
\text { distilled water: formic } \\
\text { acid in the capacity } \\
\text { ratio of } 0.5: 7.5: 0.1 \\
(\mathrm{v} / \mathrm{v} / \mathrm{v}) \text {, }\end{array}$ & $230 \mathrm{~nm}$ & $\begin{array}{l}(200-1200 \mathrm{ng} / \mathrm{spot}) \\
\text { NAP } \\
(100-1000 \mathrm{ng} / \mathrm{spot}) \\
\text { SUMA }\end{array}$ & - & 53 \\
\hline 2 & $\begin{array}{l}\text { DOM } \\
\text { and } \\
\text { NAP }\end{array}$ & Bulk & $\begin{array}{c}\text { Silica gel } 60 \\
\text { F254 }\end{array}$ & $\begin{array}{l}\text { Toluene: } \\
\text { Methanol: acetone (8: } \\
\text { 2: } 2, \mathrm{v} / \mathrm{v} / \mathrm{v}) \text {. }\end{array}$ & $266 \mathrm{~nm}$ & $\begin{array}{lr}20-140 & \\
\text { ng.spot } & \text {-DOM } \\
500-3500 & \text { ng.spot- }\end{array}$ & - & 54 \\
\hline
\end{tabular}




\begin{tabular}{|c|c|c|c|c|c|c|c|c|}
\hline & & & & & & 1- NAP & & \\
\hline 3 & $\begin{array}{l}\text { NAP } \\
\text { and } \\
\text { PAN }\end{array}$ & $\begin{array}{c}\text { Bulk and } \\
\text { tablet }\end{array}$ & $\begin{array}{c}\text { Silica gel } 60 \\
\text { F254 }\end{array}$ & $\begin{array}{lr}\text { Ethyl acetate: } & \text { glacial } \\
\text { acetic } & \text { acid } \\
(4.8: 0.2) .(\mathrm{v} / \mathrm{v}) & \end{array}$ & $310 \mathrm{~nm}$. & $\begin{array}{l}\text { NAP- } \\
50 \text { to } 300 \mathrm{ng} / \mathrm{spot} \\
\text { PENTO } \\
250 \text { to } 1500 \\
\mathrm{ng} / \mathrm{spot}\end{array}$ & $\begin{array}{c}\text { NAP- } \\
0.67 \\
\text { PENTO- } \\
0.3\end{array}$ & 55 \\
\hline 4 & $\begin{array}{l}\text { DPH } \\
\text { HCL } \\
\text { and } \\
\text { NAP }\end{array}$ & Tablets & $\begin{array}{c}\text { Silica gel } 60 \\
\text { F254 }\end{array}$ & $\begin{array}{l}\text { Toluene: methanol: } \\
\text { glacial acetic acid } \\
(7.5: 1: 0.2, \mathrm{v} / \mathrm{v} / \mathrm{v}) \text {. }\end{array}$ & $230 \mathrm{~nm}$ & - & - & 56 \\
\hline 5 & $\begin{array}{l}\text { NAP } \\
\text { and } \\
\text { PAT }\end{array}$ & $\begin{array}{c}\text { Capsule } \\
\text { dosage } \\
\text { forms }\end{array}$ & $\begin{array}{c}\text { Silica gel } \\
\text { F254 }\end{array}$ & $\begin{array}{l}\text { Toluene: Chloroform: } \\
\text { Methanol: Formic acid } \\
(3: 5: 2.1: 4.2: 0.2, \mathrm{v} / \mathrm{v} / \mathrm{v}) \text {. }\end{array}$ & $241 \mathrm{~nm}$ & $\begin{array}{l}\text { NAP- } \\
25-125 \mu \mathrm{g} / \mathrm{ml} \\
\text { PAN- } \\
4-20 \mu \mathrm{g} / \mathrm{ml}\end{array}$ & $\begin{array}{c}\text { NAP- } \\
0.41 \pm 0.02 \\
\text { PAN- } \\
0.51 \pm 0.02\end{array}$ & 57 \\
\hline
\end{tabular}

\section{Spectrophotometry methods}

Till the date, the UV-Spectrophotometry methods for determination of NAP alone and in one or more dosage forms. The Spectrofluorimetry methods have been investigated analysis of NAP in tablets. The details Spectrophotometry and Spectrofluorimetry designating the basic principle, sample matrix, $\lambda \max$ and solvent and linearity range are concise in Table 8 .

\section{Methods for analysis of NAP as a single component}

Senthil Rajan Dharmalingam et al.(2013)The simple, delica te and accurate UVSpectrophotometric technique for definin g NAP in bulk and semisolid formulation was Dignified at 3 $31 \mathrm{~nm}$. The lnearity range for NAP was discovered to be 10 $60 \mu \mathrm{g} / \mathrm{ml}$, and the system was validated for various paramet ers such as accuracy, accuracy and specificity as per guideli nes ( $\mathrm{ICH})$.Comparative usual deviation and\% recovery stan dards have been discovered to be satisfactory, representative that the suggested method is accurate and precise and can $b$ e used later in bulk and semisolid pharmaceutical formulatio $\mathrm{n}$ for repetitive NAP investigation. ${ }^{57}$

\section{Methods for analysis of NAP in combined dosage form with other drugs}

Along with many anti-inflammatory, histamine and gastrointestinal agents, NAP is applicable. Few UVspectrophotometry methods were reported for the simultaneous determination of NAP in dosage forms and simple, fast, precise, accurate and economical methods were developed for the evaluation of NAP and PANTO, DOM, PARA, RAN in tablet dosage form.

Asha Patel et al. (2014) For the simultaneous evaluation of NAP and PARA in pharmaceutical dosage form, the easy, Q-absorbance ratio UV-spectrophotometric technique was researched and validated. The chemicals used were $\mathrm{NaOH} \quad 0.1 \mathrm{~N}$. The first scheme of working simultaneous equation solving based on the identification of absorbence at two wavelengths, $257.00 \mathrm{~nm}$ ( $\lambda$ max for PARA) and $234.00 \mathrm{~nm}$ (Isoabsorptive point) were specific to the approximation of PARA and NAP for the technique of Q-absorbance proportion. To select the isoabsorbent point for evaluation, the overlay spectrum of NAP and PARA drugs was used. The chemicals used were $\mathrm{NaOH}$
$0.1 \mathrm{~N}$. The first operating system to solve simultaneous equation based on the detection of absorbence at two wavelengths, $257.00 \mathrm{~nm}$ ( $\lambda \max$ for PARA) and $234.00 \mathrm{~nm}$. linearity of the preferred technique for paracetamol was 2.5$5.0 \mu \mathrm{g} / \mathrm{ml}$ and for naproxen was 1.5-3.0 $\mu \mathrm{g} / \mathrm{ml}$. The \%recovery study was found to be corresponding to 97.9 $1 \%$ (PCM) and 98.64\%(NAX). The predicted scheme was a ccurate, selective and accurate in bulk formulation for simul taneous evaluation of NAP and PARA. Naproxen 1.5-

$3.0 \mu \mathrm{g} / \mathrm{ml}$. The\% recovery study was found to be $97.91 \%$ for (PCM) and $98.64 \%$ for (NAX) accordingly. The projected tecnique was accurate, selective and precise for simultaneous assessment of NAP and PARA in bulk formulation. $^{58}$

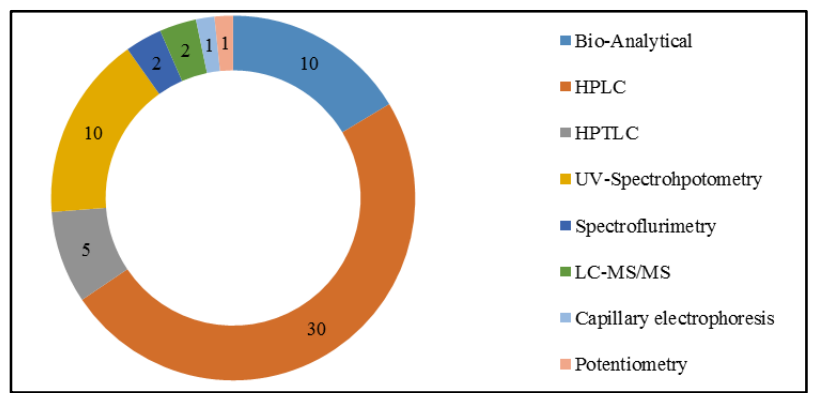

Fig. 6: Percentage Utility of Analytical Approaches used for estimation of Naproxen

Tasnuva Haque et al. (2008) reported that to simple, correct methods for the simultaneous estimation of NAP and RAN and their combined form of UV-Spectrophotometry method were studied and validated. Simultaneous equation technique (SEM) uses NAP and RAN inquiry using $313 \mathrm{~nm}$ in $\mathrm{pH} 7.4$ phosphate buffer and $314 \mathrm{~nm}$ in $0.1 \mathrm{~N}$ HCL and $\mathrm{H} 2 \mathrm{O}$ as well as NAP investigation at $229 \mathrm{~nm}$ in $\mathrm{pH} 7.4$ phosphate buffer and $232 \mathrm{~nm}$ in both $0.1 \mathrm{~N} \mathrm{HCL}$ and in $\mathrm{H}_{2} \mathrm{O}$ parallel to the specific absorption maxima. The tablet formulations were expected for the percent content of both the drugs at the designated wavelengths and the percent influence were 98.83 and 99.15 for NAP and RAN HCL respectively. ${ }^{59}$ 
Table 7: Spectrophotometric methods used for determination of NAP alone and in combine dosage form

\begin{tabular}{|c|c|c|c|c|c|c|c|}
\hline S. No & Drugs & Matrix & $\begin{array}{c}\text { Linearity } \\
(\mu \mathrm{g} / \mathrm{ml})\end{array}$ & $\begin{array}{l}\text { Coefficient } \\
\text { Correlation }\end{array}$ & $\begin{array}{c}\text { Accuracy } \\
\text { study in } \\
(\%)\end{array}$ & $\begin{array}{c}\text { LOD\&LOQ } \\
(\mu \mathrm{g} / \mathrm{ml})\end{array}$ & Ref \\
\hline 1 & NAP & $\begin{array}{l}\text { Bulk and Semi- } \\
\text { solid } \\
\text { Formulation }\end{array}$ & $10-60 \mu \mathrm{g} / \mathrm{ml}$ & 0.9984. & $80,100,120$ & $\begin{array}{l}\text { LOD- } \\
1.5357 \mu \mathrm{g} / \mathrm{ml} \\
\text { LOQ- } \\
5.1191 \mu \mathrm{g} / \mathrm{ml}\end{array}$ & 57 \\
\hline 2 & $\begin{array}{l}\text { NAP and } \\
\text { PARA }\end{array}$ & Bulk & $\begin{array}{l}\text { PARA- } \\
2.5-5.0 \mu \mathrm{g} / \mathrm{ml} \\
\text { NAP } \\
1.5-3.0 \mu \mathrm{g} / \mathrm{ml}\end{array}$ & $\begin{array}{l}\text { PARA- } \\
0.9996 \\
\text { NAP- } \\
0.999\end{array}$ & $\begin{array}{l}80,100, \\
120 .\end{array}$ & - & 58 \\
\hline 3 & $\begin{array}{l}\text { NAP AND } \\
\text { RAN-HCL }\end{array}$ & Tablet & $\begin{array}{l}\text { RAN- } \\
5-25 \mu \mathrm{g} / \mathrm{ml} \\
\text { NAP- } \\
0.2-1.25 \mu \mathrm{g} / \mathrm{ml}\end{array}$ & $\begin{array}{ll}\text { NAP- } & \\
0.9976 & \\
\text { RAN- } & \\
\alpha & 0.997\end{array}$ & - & $\begin{array}{l}\text { RAN- } \\
\text { LOD-75.205 } \\
\text { LOQ-250.685 } \\
\text { NAP- } \\
\text { LOD-1.411 } \\
\text { LOQ-4.702 } \\
\end{array}$ & 59 \\
\hline 4 & $\begin{array}{l}\text { NAP and } \\
\text { DOM }\end{array}$ & Tablet & $\begin{array}{l}\text { NAP- } \\
10-35 \mu \mathrm{g} / \mathrm{ml} \\
\text { DOM- } \\
5-30 \mu \mathrm{g} / \mathrm{ml}\end{array}$ & $\begin{array}{l}\text { NAP- } \\
0.9999 \\
\text { DOM- } \\
0.9998\end{array}$ & $\begin{array}{l}80,100 \\
120 .\end{array}$ & $\begin{array}{l}\text { NAP-LOD } \\
0 \cdot 454 \mu \mathrm{g} / \mathrm{ml} \\
\text { DOM-LOD } \\
0.657 \mathrm{mg} / \mathrm{ml} \\
\text { NAP- } \\
0 \cdot 151 \mu \mathrm{g} / \mathrm{ml} \\
\text { DOM- } \\
2.18 \mathrm{mg} / \mathrm{ml}\end{array}$ & 60 \\
\hline 5 & NAP & Tablet & $\begin{array}{l}\text { NAP- } \\
20-140 \mu \mathrm{g} / \mathrm{ml}\end{array}$ & $\begin{array}{ll}\text { NAP- } & \\
\bullet & 0.999 \\
\end{array}$ & $80,100,120$ & - & 61 \\
\hline 6 & $\begin{array}{l}\text { LNP and } \\
\text { NAP }\end{array}$ & Tablet & $\begin{array}{l}\text { LAN- } \\
5-30 \mu \mathrm{g} / \mathrm{ml} \\
\text { NAP- } \\
10-35 \mu \mathrm{g} / \mathrm{ml}\end{array}$ & $\begin{array}{l}\text { LAN- } \\
(0 \cdot 998) \\
\text { NAP- } \\
(0.999)\end{array}$ & $80,100,120$ & $\begin{array}{l}\text { NAP-LOQ } \\
0 \cdot 15 \mu \mathrm{g} / \mathrm{ml} \\
\text { LAN-LOQ } 1 \cdot 7 \mu \mathrm{g} / \mathrm{ml} \text {. } \\
\text { NAP-LOD } \\
0 \cdot 04 \mu \mathrm{g} / \mathrm{ml} \\
\text { LAN -LOD } \quad 0 \cdot 5 \mu \mathrm{g} / \mathrm{ml} \text {. }\end{array}$ & 62 \\
\hline 7 & $\begin{array}{l}\text { SUMA-S and } \\
\text { NAP-S }\end{array}$ & Tablet & $\begin{array}{l}3-18 \text { ppm for both } \\
\text { the drugs. }\end{array}$ & - & $\begin{array}{l}80,100, \\
120 .\end{array}$ & $\begin{array}{l}\text { LOD- } \\
\text { NAP-0.24 } \\
\text { SUM-0.31 } \\
\text { LOQ } \\
\text { NAP-0.74 } \\
\text { SUM-0.94 } \\
\end{array}$ & 63 \\
\hline 8 & $\begin{array}{l}\text { NAP and } \\
\text { PAN }\end{array}$ & - & $\begin{array}{l}\text { NAP- } \\
10.0-50.0 \mu \mathrm{g} / \mathrm{ml} \\
\text { PANTO- } \\
8.0-18.0 \mu \mathrm{g} / \mathrm{ml}\end{array}$ & $\begin{array}{l}\text { NAP- } \\
0.998 \\
\text { PAN- } \\
0.996\end{array}$ & - & - & 64 \\
\hline 9 & $\begin{array}{l}\text { NAP-S and } \\
\text { PAN-S }\end{array}$ & $\begin{array}{l}\text { Bulk and } \\
\text { dosage form }\end{array}$ & $\begin{array}{l}\text { NAP- } \\
02-10 \mu \mathrm{g} / \mathrm{ml} \\
\text { PAN- } \\
02-10 \mu \mathrm{g} / \mathrm{ml}\end{array}$ & $\begin{array}{l}\text { NAP- } \\
0.995 \\
\text { PAN- } \\
0.995\end{array}$ & $\begin{array}{l}\text { NAP- } \\
80,100, \\
120 . \\
\text { PAN- } \\
(6.4,8,9.6)\end{array}$ & $\begin{array}{l}\text { NAP- } \\
0.011 \mu \mathrm{g} / \mathrm{ml}, 0.0042 \\
\mu \mathrm{g} / \mathrm{ml}, \\
\text { PAN- } \\
0.0042 \mu \mathrm{g} / \mathrm{ml}, 0.0129 \\
\mu \mathrm{g} / \mathrm{ml}\end{array}$ & 65 \\
\hline 10 & $\begin{array}{l}\text { ESOM and } \\
\text { NAP }\end{array}$ & $\begin{array}{l}\text { Bulk and tablet } \\
\text { dosage form }\end{array}$ & $\begin{array}{l}\text { ESO- } \\
5-50 \mu \mathrm{g} / \mathrm{ml} \\
\text { NAP- } \\
5-50 \mu \mathrm{g} / \mathrm{ml}\end{array}$ & $\begin{array}{l}\text { ESO- } \\
0.9993 \\
\text { NAP- } \\
0.9995\end{array}$ & $\begin{array}{l}80,100 \\
120 .\end{array}$ & - & 66 \\
\hline
\end{tabular}

\section{Spectrofluorimetric methods}

Alberto Navalo'n et al. (1998) reported the different Spectrofluorimetry method, depend on measurement of native fluorescence intensity of both drugs at emission 300 $\mathrm{nm}$ and $520 \mathrm{~nm}$ is using excitation wavelength of $290 \mathrm{~nm}$. The excitation-emission spectra of these compounds are powerfully overlapped, which doesn't authorize their direct.
The concentration range was discover to be $0.1-1.0 \mu \mathrm{g} / \mathrm{ml}$ for NAP and $0.5-5.0 \mu \mathrm{g} / \mathrm{ml}$ for SA and 2.0-12.0 $\mu \mathrm{g} / \mathrm{ml}$ for ASA. To validate the accurateness of the expected technique, the improved model, obtained by PLS-1, was useful to the purpose of these compounds in pharmaceuticals and human 
serum samples earlier spiked with dissimilar amounts of each chemical. ${ }^{67}$

Patricia Damiani et al. (2002) defined a simple, sensitive and reliable Spectrofluorimetry technique for determination of Naproxen in tablets.

The fluorescence concentration was discovered to be 35 $3 \mathrm{~nm}$ using an excitation frequency of $271 \mathrm{~nm}$, and in order $\mathrm{t}$ o validate the scheme the effects were contrasted with those acquired by the USP XXIV NF 19 Pharmacopoeia reference technique (HPLC). In this concluding case a modification process is necessary. ${ }^{68}$

\section{Liquid chromatography-mass spectrometric methods}

Shanmugam Gopinath et al (2013) studied validated a simple fast method simultaneous analysis, in human plasma of NAP and ESOM using high performance liquid chromatography-tandem mass spectroscopy (LC-MS/MS). Solid-phase extraction was used to obtained analyte and internal standard from human plasma, and differentiation of analyte and internal standard was accomplish on X Bridge C18 column using acetonitrile: ammonium formate in the ratio of $(70: 30 \mathrm{v} / \mathrm{v})$. The calibration curve was linear from 3.00-700.02 $\mu \mathrm{g} / \mathrm{ml}$ for esomeprazole and 0.50-150.08 for NAP, and Mass detection was obtained by ESI/MS/MS in destructive ion mode, checking at $\mathrm{m} / \mathrm{z} 344.19$ ! 194.12, 229.12! 169.05 And 205.13! 161.07 For ESOM, NAP and IS, respectively. The evaluate is suitable for measuring perfect esomeprazole and naproxen plasma concentrations in human bioequivalence study following combined paperwork. $^{69}$

Paul W. Elsinghorst et al. (2011) established a validated sensitive, accurate quantitative liquid chromatography-mass spectroscopy (LC-MS/MS) technique for the purpose of NAP in human plasma was developed and absolutely validated permitting to present FDA and EMA guidelines. The LC-MS/MS scheme is the simultaneous accomplishment of great absolute recovery $(90.0 \pm 3.6 \%)$, the LOD were search to be $\left.0.100 \_\mathrm{g} / \mathrm{mL}\right)$, high inter-day precision $(\mathrm{CV} \leq 9.4 \%)$, high analytical recovery (between 94.4 and $103.1 \%$ ). The linearity range was selected as $0.100-50.0 \mathrm{~g} / \mathrm{mL}(\mathrm{r} 2 \geq 0.998)$ combined with a short run time of only 2 min. ${ }^{70}$

\section{Capillary electrophoresis (CE) method}

Pingping Zhang et al. (2018) Investigation of capillary electrophoresis coupling with chemiluminescence recognition scheme for influential naproxen was developed based on the improved chemiluminescence concentration of the luminol and $\mathrm{K} 3 \mathrm{Fe}(\mathrm{CN}) 6$ in alkaline solution. The disjunction was conducted in $30 \mathrm{~m}$ mol L-1 borate buffers at $\mathrm{pH} 10.0$. The linearity range was selected as $10-2000 \mu \mathrm{g} / \mathrm{ml}$, and LOD and LOQ was found to be $2.7 \mu \mathrm{g} \mathrm{L}-1$ and $8.8 \mu \mathrm{g}$ $\mathrm{L}-1$, respectively. The proposed method was useful to identify NAP in human urine sample with acceptable analyse results. $^{71}$

\section{Potentiometric methods}

Ulku Dilek Uysal et al. (2004) This paper designates the potentiometric method to quantify naproxen in tablets. The solvent system composition of aqueous solution of $20 \%$ ethanol with an ionic capacity of 0.1 additional sodium chloride has been discover to be appropriate for naproxen examination. Similar solvent system was employed for titrant of $0.1 \mathrm{~N} \mathrm{HCl}$ and to titrate the active material. Validation processes as repeatability (precision) $(n=6)$ were calculated. It was found to be 0.70 for RSD\% and 0.3 for $\pm \mathrm{CL}(\mathrm{p}=0.05)$. The analysis of 275 and $550 \mathrm{mg}$ naproxen sodium tablets was carried out in the filtered and unfiltered tablet solutions for three successive days considering intra and inter-days. Precision values were in the range of 0.16 0.33 for unfiltered and $0.10-0.29$ for filtered solutions and the amount of the tablets was found to be in the range of $(103.0-108.7 \%)$ for unfiltered and (102.9-107.7\%) for filtered solutions. The method proposed here is precise simple and rather cheap. Therefore, it is suggested for the routine analysis of naproxen sodium tablets. ${ }^{72}$

\section{Conclusion}

The present review illustrates different analytical approaches exercised for the assessment of NAP. A frequent investigation had present including, Bio-analytical, HPLC, HPTLC, UV/Vis-Spectroscopy, Spectrofluorimetry, capillary electrophoresis, LC-MS, LC-ESI-MS etc. for estimation of NAP in bulk and in its combined pharmaceutical formulations and in plasma. Liquid chromatography with UV detection has been found to be most studied for estimation of NAP in bulk and pharmaceutical dosage forms, while hyphenated LS-MS, LS-MS/MS methods are reported for determination of NAP and its metabolite in plasma and other biological fluids. Further, methods were reported for its pharmacokinetic and bioequivalence studies. Few chromatography approaches like HPTLC and Stability-indicating HPLC and HPTLC are also reported in literature. Definite Spectrophometric methods in UV-Visible along with fluorimetric are mainly often used for estimation for NAP.

\section{Abbreviations}

NAP- Naproxen; ESOM-Esomeprazole; DOMDomperidone; PARA-Paracetamol; PAN-Pantoprazole; RAN-Ranitidine; SUMA-Sumatriptan; $\boldsymbol{\lambda} \mathbf{m a x}-$ Wavelength Maxima; LIN-Linearity; FR-Flow Rate; RT-Retention Time; RF-Retention Factor; UV-VIS- UV/Visible Spectrophotometry; HPLC- High Performance Liquid Chromatography; RP-HPLC- Reverse Phase Liquid Chromatography; HPTLC- High Performance Thin Layer Chromatography; LC-MS/MS- Liquid Chromatography Mass Spectrometry/Mass Spectrometry; UPLC-MS/MSUltra Pressure Liquid Chromatography-Mass SpectrometryMass Spectrometry; ODS- Octadecyl silane; OPAOrthophosphoric Acid; IUPAC- International Union of Pure and Applied Chemistry; IP-Indian Pharmacopoeia; CmCentimetre; mm-Millimetre; nm- Nanometre; $\boldsymbol{\mu L}$ - Micro 
Litter; $\quad \boldsymbol{\mu g}$-Microgram; $\quad$ REF- Reference; DMFDimethylformamide; NaOH-Sodium Hydroxide; $\mathbf{K O H}-$ Potassium Hydroxide; ACN-Acetonitrile; $\mathbf{M e O H}-$ Methanol; EtOH-Ethanol; GAA -Glacial Acetic Acid; LOD - Limit of Detection; LOQ - Limit of Quantification.

\section{Source of Funding}

None.

\section{Conflict of Interest}

None.

\section{Reference}

1. Elsinghorst P.W, Kinzig M, Rodamer M, Holzgrabe U. and Sörgel F. An LC-MS/MS procedure for the quantification of naproxen in human plasma: Development, validation, comparison with other methods, and application to a pharmacokinetic study. J Chromatography B 2011;879(19):1686-96.

2. Muneer S, Muhammad I.N, Abrar M.A., Munir I. and Kaukab I. High Performance Liquid Chromatographic Determination of Naproxen in Prepared Pharmaceutical Dosage Form and Human Plasma and its Application to Pharmacokinetic Study. J Chromatogr Sep Tech 2017;8(369):2.

3. Filist M, Szlaska I, Kaza M. and Pawiński T, Validated HPLCUV method for determination of naproxen in human plasma with proven selectivity against ibuprofen and paracetamol. Biomedical Chromatography 2016;30(6)953-61.

4. Mahaboob subhani. syed,2014. Analytical method development and validation for simultaneous estimation of naproxen and pantoprazole in capsule dosage Form by RPHPLC. Int J Pharm Anal Res 2014;3(4):334-47.

5. Moyer S, Pharmacokinetics of Naproxen Sodium. Cephalalgia 1986;6(4):77-80.

6. Haque A, Amrohi SH, Nasare M, P Kumar.K, Pradeep Kumar.T, Nivedita.G et al, Analytical method development and validation for the estimation of naproxen using RP-HPLC. IOSR J Pharm 2012;2(4):19-24.

7. Andersen J.V. and Hansen S.H. Simultaneous quantitative determination of naproxen, its metabolite 6-Odesmethylnaproxen and their five conjugates in plasma and urine samples by high-performance liquid chromatography on dynamically modified silica. J Chromatography B: Biomed Sci Appl 1992;577(2);325-33.

8. Shirkhedkar A.A, Chaudhari S.R, Patil A.S. and Surana S.J. A Concise Review on Analytical Profile of Valsartan. Eurasian J Anal Chem 2017;12(4):337-64.

9. Pharmacopoeia-Volume III, I. (2010). Published by Indian Pharmacopoeial Commission for Ministry of Health and Family Welfare, Ghaziabad, New Delhi, pp.204, 593, 2695.

10. Shirkhedkar A.A, Chaudhari S.R, Patil A.S. and Surana S.J. A Concise Review on Analytical Profile of Valsartan. Eurasian J Anal Chem 2017;12(4):337-64.

11. Kumar S.A, Debnath M, Rao J.S. and Sankar D.G, 2014. A new bioanalytical method development \& validation for simultaneous estimation of esomeprazole and naproxen in human plasma by using RP-HPLC. Br J Pharm Res 2014;4(19):2312.

12. Yilmaz B, Asci A. and Erdem A.F. HPLC method for naproxen determination in human plasma and its application to a pharmacokinetic study in Turkey. $J$ Chromatogr Sci 2013;52(7):584-9.

13. Muneer S, Muhammad I.N, Abrar M.A, Munir I. and Kaukab I. High Performance Liquid Chromatographic Determination of Naproxen in Prepared Pharmaceutical Dosage Form and
Human Plasma and its Application to Pharmacokinetic Study. J Chromatogr Sep Tech 2017;8(369):2.

14. Filist M, Szlaska I, Kaza M. and Pawiński T. Validated HPLCUV method for determination of naproxen in human plasma with proven selectivity against ibuprofen and paracetamol. Biomed Chromatogr 2016;30(6):953-61.

15. Shanmugam G, Kumar R.S, Shankar M.B, Danabal P. Development and validation of a sensitive and high-throughput LC-MS/MS method for the simultaneous determination of esomeprazole and naproxen in human plasma. Biomed Chromatogr 2013;27;894-9.

16. Sultana N, Arayne M.S. and Iftikhar B. Simultaneous Determination of Atenolol, Rosuvastatin, Spironolactone, Glibenclamide and Naproxen Sodium in Pharmaceutical Formulations and Human Plasma by RP-HPLC. J Chin Chem Soc 2008;55(5), pp.1022-1029.

17. Sun Y, Zhang Z, Xi Z. and Shi Z. Determination of naproxen in human urine by high-performance liquid chromatography with direct electrogenerated chemiluminescence detection. Talanta 2009;79(3);676-80.

18. Kumar, S.A., Debnath, M., Rao, J.S. and Sankar, D.G. A New Bioanalytical Method Development \& Validation for Simultaneous Estimation of Esomeprazole and Naproxen in Human Plasma by Using RP-HPLC. Br J Pharm Res 2014;4(19):2312.

19. Sahoo N.K, Sahu M, Rao P.S. and Ghosh G. Development and Validation of Liquid Chromatography-Mass

Spectroscopy/Mass Spectroscopy Method for Quantitative Analysis of Naproxen in Human Plasma after Liquid-Liquid Extraction. Tropical J Pharm Res 2014;13(9):1503-10.

20. Elsinghorst P.W, Kinzig M, Rodamer M, Holzgrabe U. and Sörgel F. An LC-MS/MS procedure for the quantification of naproxen in human plasma: Development, validation, comparison with other methods, and application to a pharmacokinetic study. J Chromatography B 2011;879(19):1686-96.

21. Keyhanian F, Alizadeh N. and Shojaie A. Spectrophotometric determination of Naproxen as ion-pair with bromophenol blue in bulk, pharmaceutical preparation and human serum samples. Curr Chem Lett 2014;3(1):15-22.

22. Solanki S.D. and Patel P.U.,. Development and validation of reversed-phase high performance liquid chromatographic method for simultaneous estimation of sumatriptan succinate and naproxen sodium in pharmaceutical dosage form. Int $J$ Pharm Pharm Sci 2012;4(1):276-8.

23. Mondal M.S, Haque M.A, Islam M.S. and Islam S.A. Development and validation of RP-HPLC method for the simultaneous estimation of domperidone and naproxen in tablet dosage form. J Appl Pharm Sci 2011;1(7);145.

24. Haque A, Amrohi SH, Nasare M, P Kumar.K, P Kumar.T, Nivedita.G et al, Analytical method development and validation for the estimation of naproxen using RP-HPLC. IOSR J Pharm 2012;2(4):19-24.

25. Mehta P, Sharma C.S, Nikam D. and Ranawat M.S. Development and validation of related substances method by HPLC for analysis of naproxen in naproxen tablet formulations. Int J Pharm Sci Drug Res 2012;4(1):63-9.

26. Tsvetkova, B. RP-HPLC method for determination of naproxen in Pharmaceutical dosage form. PHARMACIA, 2015;62(3);15-9.

27. Kumar S.A, Debnath M. and Kumar V.P.K, 2016. Method development and validation for estimation of Naproxen in bulk samples as well as in tablet dosage forms by using RPHPLC. Pharma Tutor 2016;4(9);33-9.

28. Rao K.T. and Rao L.V, A validated stability-indicating UHPLC method for determination of naproxen and its related 
compounds in bulk drug samples. Am J Anal

Chem 2013;4(06), p.286.

29. Solanki S.D. and Patel P.U. Development and validation of reversed-phase high performance liquid chromatographic method for simultaneous estimation of sumatriptan succinate and naproxen sodium in pharmaceutical dosage form. Int $J$ Pharm Pharm Sci 2012;4(1);276-8.

30. Razzaq S.N, Ashfaq M, Khan I.U. and Mariam I. Development and validation of liquid chromatographic method for naproxen and esomeprazole in binary combination. J Chilean Chemical Soc 2012;57(4):1456-9.

31. Mondal M.S, Haque, M.A, Islam M.S. and Islam S.A, Development and validation of RP-HPLC method for the simultaneous estimation of domperidone and naproxen in tablet dosage form. J Appl Pharm Sci 2011;1(7):145.

32. Shekhar C.E, Kumar R.S, Sankar R.M. and Prasanti P. Simultaneous Estimation of Naproxen Sodium and Domperidone Maleate in Bulk and Pharmaceutical Dosage Form by Modified RP-HPLC Method. Int J Pharm Chemical Sci 2012;1(4).

33. Vani P. and Kottapalli K.S. Development and validation of RP-HPLC method for simultaneous estimation of naproxen and esomeprazole in pharmaceutical dosage form. Int J Pharm Technol, 2011;3:3446-55.

34. Debnath M, Kumar S.A, Anguluri D.P, Sri G.P, Ramya J.V.L.N. and Sankar D.G et al, An analytical method development and validation for simultaneous estimation of Sumatriptan and Naproxen in bulk samples as well as in tablet dosage forms by using RP-HPLC.

35. Mohideen S, Shivakanth M, SureshKumar P, Krishnan S.N, Surendranath Y. and Satyanarayana T. Development and validation of analytical method for naproxen and pantoprazole in capsule dosage form. Der Pharm Sinica, 2011;2(6):114-21.

36. M subhani. syed, Analytical method development and validation for simultaneous estimation of naproxen and pantoprazole in capsule dosage Form by RP-HPLC. Int $J$ Pharm Anal Res 2011;3(4):334-7.

37. Jain D.K, Jain N, Charde R. and Jain N. The RP-HPLC method for simultaneous estimation of esomeprazole and naproxen in binary combination. Pharm Method 2011;2(3):167-72.

38. Bhuyian, M.H.U., Development and validation of method for determination of esomeprazole and naproxen from cobination product by HPLC.

39. Reddy P.S, Sait S, Vasudevmurthy G, Vishwanath B, Prasad V. and Reddy S.J. Stability indicating simultaneous estimation of assay method for naproxen and esomeprazole in pharmaceutical formulations by RP-HPLC. Der Pharma Chemica 2011;3(6):553-64.

40. Khan M.F, Zuthi S.S, Kayser M.S, Islam M.S, Asad S. and Rashid M.A, A Simple RP-HPLC Method Development and Validation for the Simultaneous Estimation of Naproxen and Rabeprazole. J Appl Pharm Sci 2016;6(11);147-52.

41. Vasanthi R, Sumathi B, M Alagar Raja, V. Shirisha, Banji D, Kumar DS, Analytical method development and validation for the simultaneous estimation of sumatriptan and naproxen in bulk and pharmaceutical dosage form by RP-HPLC. Asian $J$ Pharm Anal Med Chem 2015;3(3):137-44.

42. Ekpe A, Tong J.H. and Rodriguez L, High-performance liquid chromatographic method development and validation for the simultaneous quantitation of naproxen sodium and pseudoephedrine hydrochloride impurities. J Chromatographic Sci 2001;39(3);81-6.

43. Gondalia R. and Dharamsi A, Simultaneous estimation of sumatrirtan succinate and naproxen sodium in bulk drug and pharmaceutical dosage form by RP-HPLC method. J Drug Delivery Ther 2013;3(2).
44. Reddy Y.R, Kumar K.K, Reddy M.R.P. and Mukkanti K, Rapid simultaneous determination of sumatriptan succinate and naproxen sodium in combined tablets by validated ultraperformance liquid chromatographic method. J Anal Bioanalytical Tech 2011;2(3):1-6.

45. Singh K.B, Waikar S.B. and Padmane S.P, A validated RPHPLC method for the simultaneous estimation of paracetamol and naproxen in tablet formulation. Int J Pharm Sci Res 2011;3(11);4270.

46. Kumar S.A, Debnath M. and Rao J.S. Simultaneous estimation of Esomeprazole and Naproxen in bulk as well as in pharmaceutical formulations by using RP-HPLC. Int J Pharm Sci Res 2013;4(8):2988.

47. Wahbi, A.A.M., Mabrouk, M.M., Moneeb, M.S. and Kamal, A.H., 2009. Simultaneous determination of the two nonsteroidal anti-inflammatory drugs; diflunisal and naproxen in their tablets by chemometric spectrophotometry and HPLC. Pak J Pharm Sci 22(1).

48. Haque M.A, Shahriar M, Parvin M.N. and Islam S.A, Validated RP-HPLC method for estimation of ranitidine hydrochloride, domperidone and naproxen in solid dosage form. Asian J Pharm Anal 2011;3:59-63.

49. Dinç E, Özdemir A, Aksoy H, Üstündağ Ö. and Baleanu D. Chemometric determination of naproxen sodium and pseudoephedrine hydrochloride in tablets by HPLC. Chem Pharm Bull 2006;54(4):415-21.

50. Kayesh R. and Sultan M.Z. A novel ion-pair RP-HPLC method for simultaneous quantification of naproxen and esomeprazole in pharmaceutical formulations. J Chromatographic Sci 2014;53(5):687-93.

51. SV, D., Mahaparale, S., Shinde, S. and Funne, S., Development and Validation of Esomeprazole and Naproxen in Bulk and Tablet Dosage Form by RP-HPLC Method. Dev 2(5).

52. Nalluri B.N, Mrudula B, Chitralatha K, Sultana S.A. and Chandra, T.U. Development of stability indicating RP-HPLCPDA method for the simultaneous analysis of naproxen sodium and diphenhydramine hydrochloride in bulk and tablet dosage forms. Indian Drugs 2015;52(9):9.

53. Gondalia R. and Dharamsi A. HPTLC method for simultaneous determination of Naproxen sodium and Sumatriptan succinate in pharmaceutical dosage form. Int $J$ Pharm Sci Res 2011;2(1);130-4.

54. Pawar S.M, Patil B.S. and Chaudhari R.Y. Validated HPTLC method for simultaneous quantitation of domperidone maleate and naproxen sodium in bulk drug and formulation. Eurasian $J$ Anal Chem 2010;5(3):284-92.

55. Patil A. and Mulla S. Development and Validation of HPTLC Method for the Simultaneous Estimation of Naproxen and Pantoprazole in Combined Dosage Form. Int J Pharm Pharm Sci 2013;5:223-5.

56. Bhole R.P, Shinde S.S., Chitlange S.S. and Wankhede S.B. A high-performance thin layer chromatography (HPTLC) method for simultaneous determination of diphenhydramine hydrochloride and naproxen sodium in tablets. An Alytical Chem Insights 2015;10:ACI-S31506.

57. Dharmalingam S.R, Ramamurthy S, Chidambaram K. and Nadaraju S. Development and validation of UV spectrophotometric method for the estimation of naproxen in bulk and semi-solid formulation. Int J Anal Pharm Biomed Sci 2013;2:49-55.

58. Patel A., Firke S.D., Bari S.B. and Ranoliya J.R,. Development and Validation of Uv-Spectrophotometric Method for Simultaneous Estimation of Naproxen and Paracetamol by QAbsorbance Ratio Method. Int J Pharm Res Allied Sci 2014;3:57-63. 
59. Haque T, Talukder M.M.U, Laila S, Fatema K. and Kabir A.K.L. Simultaneous estimation of naproxen and ranitidine $\mathrm{HCl}$ by using UV spectrophotometer. Stamford J Pharm Sci 2008;1(1):18-24.

60. Singh S, Sharma S, Yadav A.K. and Gautam H,. Simultaneous Estimation of Naproxen and Domperidone Using UVspectrophotometry in Tablet Dosage Form. Bull Pharm Res 2013;3(2):66-70.

61. AD P.K., Sunitha G., Venkat Raju Y, Rama Krishna K, Swathi B., Praveen C.H et al. Novel spectrophotometric estimation of Naproxen Tablet formulations using sodium citrate as hydrotropic solubilizing agent. Asian J Res Chem 2011;4(5):845-7.

62. Choudhary N, Siddiqui I, Rai J, Singh S, Surabhi S. and Gautam H, Simultaneous estimation of lansoprazole and naproxen by using UV spectrophotometer in tablet dosage form. Der Pharma Chemica, 2013;5(2):67-74.

63. Solanki, S.D., Patel, P.U. and Suhagiya B.N. Development and validation of spectrophotometric method for simultaneous estimation of sumatriptan succinate and naproxen sodium in pharmaceutical dosage form. JPSBR, 2011;1:50-3.

64. Sloka S.N, Gurupadayya B.M. and Kumar C.A, Simultaneous spectrophotometric determination of Naproxen and Pantoprazole in pharmaceutical dosage form.2011.

65. Kumar R.S, Pamireddy P, Emmadi C.S. and Koneru S, Simultaneous determination of naproxen sodium and pantoprazole sodium in bulk and pharmaceutical dosage form by validated ultra-violet spectrophotometric method. PAN, 2012;20(19.97):99-8.

66. Mahaparale S.P., Mahaparale P.R. and Gonjari, I.D. Simultaneous spectrophotometric estimation of esomeprazole and naproxen in bulk and tablet dosage form. Int J Res Dev Pharm Life Sci 2013;2(2):377-82.
67. Navalón A, Blanc R, del Olmo, M. and Vilchez J.L. Simultaneous determination of naproxen, salicylic acid and acetylsalicylic acid by spectrofluorimetry using partial leastsquares (PLS) multivariate calibration. Talanta, 1999;48(2):469-75.

68. Damiani P, Bearzotti M. and Cabezón M.A. Spectrofluorometric determination of naproxen in tablets. Journal of pharmaceutical and biomedical analysis, 2002;29(1-2):229-38.

69. Shanmugam G,. Kumar R.S, Shankar M.B, Danabal P, Development and validation of a sensitive and high-throughput LC-MS/MS method for the simultaneous determination of esomeprazole and naproxen in human plasma. Biomedical Chromatography 2013;27:894-9.

70. Elsinghorst, P.W., Kinzig, M., Rodamer, M., Holzgrabe U. and Sörgel F, An LC-MS/MS procedure for the quantification of naproxen in human plasma: Development, validation, comparison with other methods, and application to a pharmacokinetic study. Journal of Chromatography B, 2011;879(19):1686-96.

71. Zhang, Sun Y, Xue H, Wang X, Lian K, Determination of naproxen in human urine by capillary P electrohpoeresis with chemiluminescence detection. Global Drugs Ther 2018;3(5):15 .

72. Uysal Ü.D. and Tunçel M, Determination of naproxen in tablets by using first derivative potentiometry. Prostaglandins 2004;1:2.

How to cite this article: Jain P. A concise review on analytical profile of naproxen. Int $J$ Comprehensive $A d v$ Pharmacol 2019;4(3):70-81. 